\title{
User fee exemptions and excessive household spending for normal delivery in Burkina Faso: the need for careful implementation
}

\author{
Amal Ben Ameur ${ }^{1}$, Valéry Ridde ${ }^{2,3^{*}}$, Aristide R Bado ${ }^{4}$, Marie-Gloriose Ingabire ${ }^{1}$ and Ludovic Queuille ${ }^{2}$
}

\begin{abstract}
Background: In 2006, the Parliament of Burkina Faso passed a policy to reduce the direct costs of obstetric services and neonatal care in the country's health centres, aiming to lower the country's high national maternal mortality and morbidity rates. Implementation was via a "partial exemption" covering 80\% of the costs. In 2008 the German NGO HELP launched a pilot project in two health districts to eliminate the remaining 20\% of user fees. Regardless of any exemptions, women giving birth in Burkina Faso's health centres face additional expenses that often represent an additional barrier to accessing health services. We compared the total cost of giving birth in health centres offering partial exemption versus those with full exemption to assess the impact on additional out-of-pocket fees.
\end{abstract}

Methods: A case-control study was performed to compare medical expenses. Case subjects were women who gave birth in 12 health centres located in the Dori and Sebba districts, where HELP provided full fee exemption for obstetric services and neonatal care. Controls were from six health centres in the neighbouring Djibo district where a partial fee exemption was in place. A random sample of approximately 50 women per health centre was selected for a total of 870 women.

Results: There was an implementation gap regarding the full exemption for obstetric services and neonatal care. Only $1.1 \%$ of the sample from Sebba but $17.5 \%$ of the group from Dori had excessive spending on birth related costs, indicating that women who delivered in Sebba were much less exposed to excessive medical expenses than women from Dori. Additional out-of-pocket fees in the full exemption health districts took into account household ability to pay, with poorer women generally paying less.

Conclusions: We found that the elimination of fees for facility-based births benefits especially the poorest households. The existence of excessive spending related to direct costs of giving birth is of concern, making it urgent for the government to remove all direct fees for obstetric and neonatal care. However, the policy of completely abolishing user fees is insufficient; the implementation process must have a thorough monitoring system to reduce implementation gaps.

\section{Background}

In order to improve maternal health and achieve Millennium Development Goal 5 (MDG5), African countries introduced different approaches to reduce barriers that limit women's access to primary health services [1]. Out-

\footnotetext{
* Correspondence: valery.ridde@umontreal.ca

${ }^{2}$ Centre de recherche du Centre Hospitalier de l'Université de Montréal,

Montréal, Québec (CRCHUM), Canada

${ }^{3}$ Department of Social and Preventive Medicine, Université de Montréal,

Montréal, Québec, Canada

Full list of author information is available at the end of the article
}

of-pocket fees are one of these barriers. They constitute a financial burden, usually associated with catastrophic expenditures that either push already vulnerable households into poverty or worsen their poverty situation [2]. In the early 1980s, many African countries adopted structural adjustment policies that led to the introduction of user fees in the health sector. This required users to pay for delivery-related health services received.

The situation has evolved since then, and today there is a growing shift, globally and particularly in Africa, to reduce financial barriers to health care. There is now a

\section{Biomed Central}


consensus that user fees often constitute a significant barrier to rational service use. They also increase the inequity gap amongst different socio-economic groups in terms of access to primary health care [3]. Due to the adverse effects of user fees on access to basic services, many organizations and governments advocate the removal of these fees. The focus has been on exempting specific services and targeting the most vulnerable [4-6]. Our study will cover a rural region in Burkina Faso, a West African country with high levels of maternal mortality (560/ 100000 live births; range: 300-950) [7] and widespread poverty (46.4\% population living below the poverty line) [8].

\section{Government interventions}

The Government of Burkina Faso is committed to improving access to maternal care. To reduce the maternal mortality and morbidity levels, the government decided in 2006 to subsidize the direct costs of obstetric care (OC) and neonatal services at $80 \%$ of the total cost. This would reduce financial barriers and encourage women to make greater use of these services. Beneficiaries pay the remaining $20 \%$ of the medical costs at primary health centres (CSPS). Where a normal institutional birth costs $4500 \mathrm{~F} \mathrm{CFA}(\approx 9$ US\$), the government pays 3600 F CFA $(\approx 7$ US $\$)$ while the birth mother pays the remaining $20 \%$, or $900 \mathrm{~F}$ CFA $(\approx 2$ US\$). The government exemption applies to the total cost of the medical procedures, drugs and consumables, and observation. In addition, the government policy includes the costs for any needed referral by public ambulance to a district or regional hospital in case of a complication. Since 2004, traditional birth attendants have been encouraged to promote medically assisted births rather than assisting in home births [9].

\section{NGO complementary interventions}

In 2008, a German NGO (HELP) funded by the European Commission of Humanitarian Office (ECHO) began work in Burkina Faso to improve access to quality health care for pregnant women. A HELP pilot project covers two rural districts of Sebba and Dori in the northeastern part of Burkina Faso, and offers a full exemption by covering the $20 \%$ of costs not covered by the government. The main activities of the NGO are the following: 1) subsidize health care for pregnant women 2) control the exemption system in the pilot districts 3) improve, monitor, and supervise quality of care to pregnant women. Every month, HELP reimburses each CSPS as per their report of real expenditures related to maternal services. Through this intervention, HELP provides added financial protection to households living in the pilot districts by reducing the costs related to an institutional birth.
There are few studies in West Africa examining the effects of user fee exemption policies on the reduction of birth-related expenses and financial protection of households. Thus, the objective of this paper is to investigate the impact of these interventions on the out-of-pocket expenditures of households for non-complicated institutional births in three rural health districts of Burkina Faso. To compare the excessive medical expenses of households receiving the partial exemption (controls) with those receiving the full exemption (cases), we carried out a case-control study in the districts where the NGO-sponsored pilot project resulted in a full exemption from user fees and in a neighbouring district where the government's partial exemption applied. The findings from this study will allow different health system stakeholders to compare costs and benefits of abolishing user fees versus the current policy of partially subsidizing the costs of institutional births. The ultimate objective of the NGO intervention is to scale it up to the national level through a policy in line with the principle of universal access to primary health care in order to benefit the population accessing health care services. [10]. Thus, stakeholders will need to find strategies to improve successful implementation of exemption models.

\section{Methods}

\section{Study site}

In this study, researchers are analysing the results of a natural experiment. A natural experiment is an empirical study in which the experimental conditions are determined by nature or by other factors out of the control of the evaluators [11]. The study took place in the Sahel Region of Burkina Faso about $300 \mathrm{~km}$ from the capital Ouagadougou, which has specific geographical and cultural characteristics. This region has four districts: Dori, Sebba, Djibo and Gorom-Gorom. The first two represent the only districts where the NGO intervened during the study; the evaluators had no control in selecting these districts for the pilot project. In order to select a third district for comparison with Dori and Sebba we examined the level of facility-based delivery (expressed as a percentage of all institutional deliveries) in GoromGorom and Djibo. According to Annuaire statistique 2009 (Ministère de la santé - Secrétariat général, Direction générale de l'information et des statistiques sanitaires), $22 \%$ of institutional deliveries in Gorom-Gorom had skilled care, while this proportion was $52.4 \%$ in Djibo. Djibo was chosen as the comparison district because its percentage of skilled care was much closer to the proportions observed in the Dori and Sebba districts. Dori and Sebba served as the case districts with a full user fee exemption provided by a pilot project of the NGO HELP, and Djibo as the control district with the government-mandated partial user fee exemption. The 
table below describes the main characteristics of the three districts (Table 1).

\section{Health centre selection and population sampling}

In every district, six health centres were selected for a total of 18 health centres ( $30 \%$ of the total centres). This selection sample was based on two previous studies in the region that reflected situational diversity [12] [13]. Only two exceptions were made because of access constraints due to the rainy season at the time of data collection. For these two cases, two other CSPS with similar characteristics were chosen.

The selection sample includes only women who gave birth in health centres and had no complications, as the study focused on expenses related to an institutional birth.

In the full exemption districts (Dori and Sebba), the study population was women who gave birth in health centres two months prior to the start of the study. In the partial exemption district (Djibo), the study population was women who gave birth in health facilities in the six months prior to the start of the study. This longer recall period was needed to gather a large enough sample size because the number of women using facility-based services in that district was very low. At the CSPS level, the sampling was done using maternal registers available in each health centre. A random sample of approximately 50 women per health centre was selected from the registers. The survey size was limited to 50 per health centre due to the limited financial resources available for the study. In Dori and Sebba it was possible to achieve this target. However, in Djibo, the low rate of facility-based births (2010) together with an exceptional number of emigrants made it more difficult to reach our targeted sample size. Thus, the final sample in this district was 270 women rather than 300 . The total sample was 870 women who gave birth in 18 health centres. Twenty-one women were excluded from the original sample as they were found to have given birth at home or before reaching the health centre (see Table 2).

\section{Survey instruments}

Survey instruments were developed based on a similar survey conducted in another district of Burkina Faso in 2006 by IMMPACT researchers and in 2010 by VR and $A B$ in Ouargaye [14]. The instruments measure medical household expenditures related to institutional birth at the point of use. The medical expenditures include: user fees, drugs and consumables, laboratory fees, and cleaning products.

Traditional poverty measurements based on consumption or incomes were particularly difficult in the sample district settings. Instead, household characteristics and asset ownership are widely used as indicators of wealth [15]. Consequently, a series of questions related to the specific characteristics of rural households in Burkina Faso was used to gauge household economic status. Questionnaires and consent forms were developed in

Table 1 Districts characteristics (source: Plans d'Action 2010 des Districts Sanitaires de la Région du Sahel)

\begin{tabular}{|c|c|c|c|}
\hline \multirow[t]{2}{*}{ Characteristics } & \multicolumn{3}{|c|}{ District } \\
\hline & Sebba & Dori & Djibo \\
\hline Government intervention (partial exemption In 2007) & Yes & Yes & Yes \\
\hline NGO HELP intervention (total exemption In 2008) & Yes & Yes & No \\
\hline Official cost of normal delivery to woman* & O FCFA & 0 FCFA & 900 FCFA \\
\hline Total population (2010) & 179819 & 295027 & 389839 \\
\hline Surface $(\mathrm{km} 2)$ & 6591 & 6920 & 12273 \\
\hline Population below the poverty line (\%) (2003) & $52 \%$ & $44.6 \%$ & $37,2 \%$ \\
\hline Main religion represented & Islam & Islam & Islam \\
\hline Main ethnicity represented & Peulh & Peulh & Peulh \\
\hline Facility-based delivery (\%) (2008)** & $47.2 \%$ & $34.8 \%$ & $41.0 \%$ \\
\hline Facility-based delivery (\%) (2009)** & $77.8 \%$ & $52.6 \%$ & $52.4 \%$ \\
\hline Facility-based delivery (\%) (2010)** & $91.2 \%$ & $59.9 \%$ & $51.2 \%$ \\
\hline Facility-based delivery (\%) $(2011)^{* *}$ & $96.6 \%$ & $70,0 \%$ & $55,0 \%$ \\
\hline Health infrastructure (2010) & $\begin{array}{l}1 \text { district hospital } \\
11 \text { CSPS }\end{array}$ & $\begin{array}{l}1 \text { regional hospital } \\
18 \text { CSPS } 1 \text { military clinic }\end{array}$ & $\begin{array}{l}1 \text { district hospital } 30 \text { CSPS } \\
1 \text { military clinic } 3 \text { private health facilities }\end{array}$ \\
\hline \multicolumn{4}{|c|}{$\begin{array}{l}\text { (*) The official cost of delivery corresponds to " acts, medicines and consumables, and observation » (Ministère de la santé, } 2006 a) . \\
\left.{ }^{* *}\right) \text { Annuaire statistique } 2008,2009,2010,2011 \text { Ministère de la santé - Secrétariat général, Direction générale de l'information et des statistiques sanitaires. } \\
\text { NGO= Non government organization. } \\
\text { CSPS= Centre de santé et de protection sociale, i.e. "first line health centre". } \\
\text { F CFA= Franc de la Communauté Financière Africaine. } \\
\text { " facility-based delivery » refers to facility-based childbirths assisted by professionals. According to the Annuaire Statistique where the indicator comes from, it is } \\
\text { called in French: Accouchements assistés par du personnel de santé. }\end{array}$} \\
\hline
\end{tabular}


Table 2 Sampling

\begin{tabular}{|c|c|c|c|c|}
\hline Districts & Sebba & Dori & Djibo & Total \\
\hline Government intervention (partial exemption) & Yes & Yes & Yes & - \\
\hline NGO HELP intervention (total exemption) & Yes & Yes & No & - \\
\hline Total deliveries $(N)$ in 6 health centres 1 & $687^{*}$ & $549 *$ & $391^{* *}$ & 1627 \\
\hline Random sampling & 299 & 301 & 270 & 870 \\
\hline Outliers (home delivery /on the way) & 9 & 8 & 4 & 21 \\
\hline Total (n) deliveries selected & 290 & 293 & 266 & 849 \\
\hline
\end{tabular}

(1) Source: maternal registers available in health centres Period of delivery: *March 2010- May 2010; **December $2009-$ May 2010.

French and then translated into the local language, Peulh, following the double-translation method. The instruments were pretested in the Dori district in a CSPS not included in the sample. The pre-test assessed the validity of the data-collection instruments and procedures, as well as the sampling procedures. This process identified content and logistical issues that led to revising some of the questions and the data collection process.

\section{Data collection}

Sahel Regional Authorities approved the survey. Fieldwork was conducted over a five-week period starting in May 2010 by six trained local interviewers fluent in Peulh and French. Each interviewer interviewed +/- 50 women over a ten-day period. The household survey questionnaires were administered to all study participants. Respondents gave verbal consent to the interview and were assured of data confidentiality. Two research coordinators carefully supervised data collection during the entire fieldwork.

\section{Data analysis}

Data was input and validation was performed with the double entry method using Epi Data software, and the data set was then converted to SPSS 17 and STATA 11 for analysis. Analysis of variance (ANOVA) was performed to compute means of medical expenses and compare them between districts and other explanatory variables (education, distance, etc.).

A poverty proxy was developed using household data indicators. Through Principal Components Analysis (PCA), households/women were assigned to poverty quintiles [16]. This allows a classification of households from the poorest (rated as 1) to the least poor (rated as 5 ) in order to show socio-economic differences.

As we did not have information about household consumption and/or income, it is not possible to measure catastrophic expenditures related to births health centres. Instead, we relied upon the concept of "high delivery health care spending per household", equivalent to "excessive spending per household". It was estimated by analyzing the expenditures dispersion within the two samples (full exemption vs partial exemption group). By using the statistical outlier method (or Tukey method) it was possible to identify the value threshold. Supposing Q1 and Q3 are respectively the first and third quartiles of the distribution of delivery health expenditure of the sample, then a high-spending or outlier household within the group is one for which the value of delivery health expenditure is greater than Q3+k*(Q3-Q1), where $\mathrm{k}$ is a constant (varied from $0.5,1$ or 1.5 ). Having three values for $k$, rather than one, allows more flexibility in defining the outlier households at different expenditure cut-off points and permits testing the sensitivity of the results. In fact, the smaller $\mathrm{k}$ is, the stricter is the approach [17].

\section{Ethics statement}

The Ministry of Health of Burkina Faso examined and approved the ethics component of this research project and authorized the study. Ethical approval was given prior to data collection.

\section{Results}

\section{Sample characteristics}

The socio-economic and demographic status of the sample households is presented in Table 3. The table shows that social, economic, and demographic characteristics are very similar within the three districts. The table shows a difference in the variable "distance from home to health facility". In fact, women selected from Dori and Djibo lived nearer the health centres than did study subjects from Sebba. Despite this observed difference, the sample characteristics are fundamentally comparable (see Table 3).

\section{Medical expenses distribution}

The distribution of the medical expenditures is illustrated in Figure 1. This figure represents Box plot, a visual representation of both central tendency and dispersion of the total medical expenses of the three samples. It simultaneously shows the 25th, 50th (median), and 75th percentile scores, along with the minimum and maximum scores. It is used to compare total 
Table 3 Sample characteristics by districts

\begin{tabular}{|c|c|c|c|c|}
\hline \multirow[t]{3}{*}{ Variables } & \multicolumn{4}{|c|}{ Districts } \\
\hline & Sebba & Dori & Djibo & Total \\
\hline & $\%$ & $\%$ & $\%$ & $\%$ \\
\hline \multicolumn{5}{|l|}{ Age } \\
\hline $15-24$ & 53.8 & 55.3 & 56.8 & 55.2 \\
\hline $25-34$ & 35.5 & 35.8 & 36.8 & 36.0 \\
\hline 35 and more & 10.7 & 8.9 & 6.4 & 8.7 \\
\hline \multicolumn{5}{|l|}{ Ethnic group } \\
\hline Peulh & 73.4 & 86.7 & 68.0 & 78.4 \\
\hline Gourmatché & 22.4 & 0.7 & 0,4 & 8 \\
\hline Mossi & 2.4 & 4.8 & 30.1 & 11.9 \\
\hline Other & 1.4 & 1 & 1.5 & 1.3 \\
\hline \multicolumn{5}{|l|}{ Matrimonial status } \\
\hline Single & 0 & 2 & 0 & 0.7 \\
\hline (Married) monogamous & 82.1 & 82.3 & 77.8 & 80.8 \\
\hline (Married) polygamous & 17.9 & 15.7 & 22.2 & 18.5 \\
\hline \multicolumn{5}{|l|}{ Education level } \\
\hline No school & 81.4 & 84.0 & 91.4 & 85.4 \\
\hline Literacy & 11.4 & 8.9 & 4.9 & 8.5 \\
\hline Primary school & 5.9 & 4.4 & 2.6 & 4.4 \\
\hline Secondary and more & 1.4 & 2.7 & 1.1 & 1.8 \\
\hline \multicolumn{5}{|l|}{ Parity } \\
\hline Primiparous & 28.7 & 25.9 & 24.9 & 26.5 \\
\hline Multiparous (2 to 4) & 71.3 & 75.4 & 77.5 & 74.6 \\
\hline High multiparous (5 and more) & 0 & 21.1 & 12.1 & 11.1 \\
\hline \multicolumn{5}{|c|}{ Distance from home to health facility } \\
\hline$\underline{\text { Less than } 5 \mathrm{~km}}$ & 34.1 & 61.4 & 65.0 & 53.2 \\
\hline $5-9 \mathrm{~km}$ & 37.9 & 27.6 & 25.6 & 30.5 \\
\hline $10 \mathrm{~km}$ and more & 22.1 & 10.6 & 9.4 & 14.1 \\
\hline N/D & 5.9 & 0.3 & 0 & 2.1 \\
\hline
\end{tabular}

medical household expenditures within and between the three districts (see Figure 1).

The figure illustrates significant differences in medical expenses distribution between the three groups. In fact, medical expenses are lower and the distribution is reduced for all the sample women in Sebba, where there is a full exemption. However, in Dori, where there is a full exemption as well, the box plot shows a large distribution of medical expenses. In Djibo, the partial exemption district, the distribution of total medical expenses appears systematically higher than the "fixed price" of 900 F CFA.

To complement the figure, Table 4 describes the medical expenses distribution according to the type of expenditure made by the households. In this context, it is also essential to identify not only the amount but also the nature of expenses at the point of use.

The table shows significant difference in the expenses (median) between the three groups. The first line of user fees shows that in Djibo, women in the partial exemption district had to pay user fees, as expected. However, a few women in Dori and Sebba testified to expenses related to user fees for childbirth, while it should be free for them. In addition, in the three districts, women spent additional amounts on medicines and consumables while all "procedures, drugs and consumables, and observation" are supposed to be included in the official user fee [18]. In fact, a delivery kit includes all the drugs and consumables used in a non-complicated birth at a primary health centre. This kit is part of the government policy implementation plan. Dori seems to be the district with a greater percentage of women paying for medicines and consumables. There is a significant difference of medical expenses between Dori and Sebba, even though they both have the same intervention for full exemption. Finally, the majority of the women had to pay for cleaning products at the point of use. Neither the NGO nor the government exemption included the cost of cleaning products. In both cases, women had to pay for cleaning products used to clean the delivery room after use.

\section{Excessive spending for households}

To assess the impact of health expenditures burden related to an institutional birth, households with excessive health care costs were analysed. This indicator aims to capture empirically the risk of impoverishment related to childbirth and household medical care costs (see Table 5).

At any given value of $\mathrm{k}$, the prevalence of households with excessive expenditures is much higher in the partial exemption district (Djibo) compared to Sebba, the only district with almost no excessive spending for households $(1.1 \% ; \mathrm{k}=0,5)$. In addition, for two of the three $\mathrm{k}$ values, there are no households with excessive expenditure in Sebba where deliveries are free of charge. On the other hand, the comparison between Dori and Djibo is quite unexpected. The percentage of households at risk is very similar in the two districts, even if there are fewer women with excessive expenditures in Dori than Djibo. The comparison between the two districts with the full exemption (Sebba and Dori) demonstrates that Dori has many more households with excessive expenditures than Sebba. Finally, we can observe that for Dori and Djibo, the medical expenses cut-off level is higher for higher values of $k$. At any given value of $k$ relative and absolute differences are about the same.

\section{Socio-economic status of household at risk}

After looking at the percentage of households with excessive spending in the two groups, table 6 demonstrates the distribution of excessive spending across the socio economic categories (Quintiles). This deeper analysis 


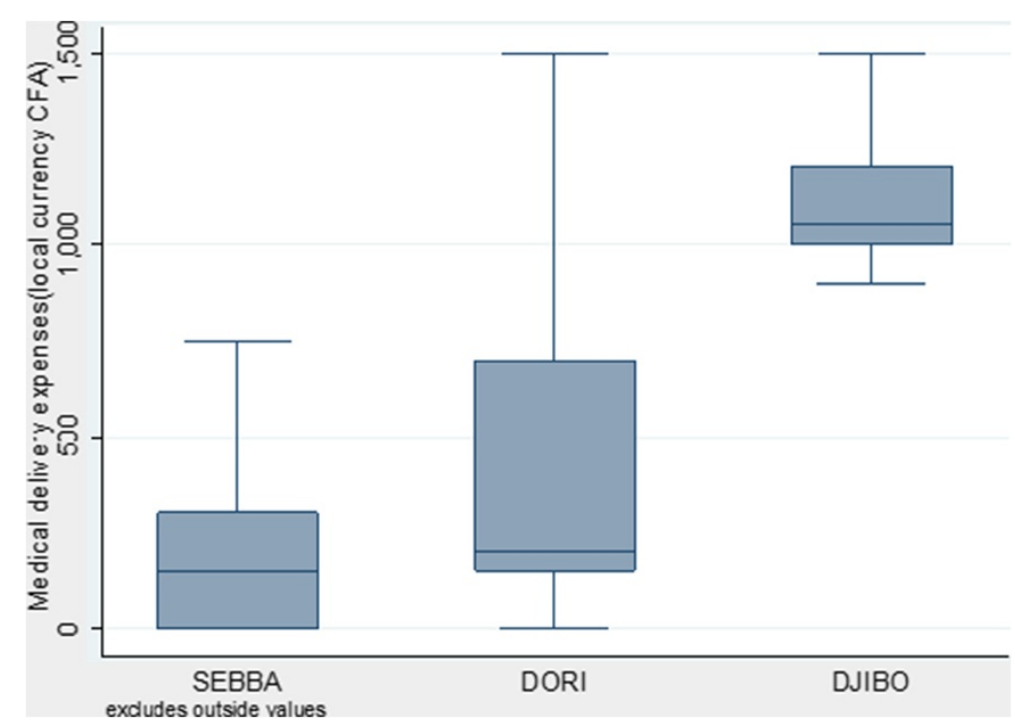

Figure 1 Distribution of total medical delivery expenses in the three districts. Median, interquartile gap and extreme values.

allows a better understanding of the distribution of the beneficial effect of the user fee related interventions on the poorest and least poor of the region (see Table 6).

In the district of Sebba, the poorest seem to reap a greater benefit from the total fee exemption than the less poor. At any level of $\mathrm{k}$, the prevalence of excessive expenses is higher in Djibo and Dori than in Sebba. In addition, the gap between the poor and the less poor related to excessive spending is large in both Dori and Djibo. Finally, we can observe that in the whole sample, the less poor are more at risk of having excessive expenses related to institutional childbirth than the poorest quintile. This gap is more accentuated in Sebba and Dori. This finding implies that the greater the household capacity to pay, the more the household will spend at the facility for medical charges. This last association needs to be further explored in the field.

\section{Discussion}

The pro-poor benefit of user fee exemption

There is extensive literature on the impact of abolishing user fees on women's use of health services. For instance, a recent study analysed the effectiveness of the exemption policy and the distribution of its benefits in Burkina Faso. By reducing household expenses, all categories of the population benefited from this policy, including the poorest. However, subsidizing medical costs did not reduce inequalities in the way pregnant women used healthcare. In fact, to improve service utilization by the poorest and reduce expenses more significantly for women living far from health centres, lowering healthcare costs is probably not enough. There are still other financial and geographic barriers to access that need to be removed to increase institutional care for the poorest [14].

There is a consensus that removing or reducing financial barriers increases the number of institutional births.

Table 4 Detail of medical expenses distribution by district

\begin{tabular}{|c|c|c|c|c|c|c|c|c|c|c|c|c|c|c|c|}
\hline & \multicolumn{4}{|c|}{ Sebba (1) } & \multicolumn{4}{|c|}{ Dori (2) } & \multicolumn{4}{|c|}{ Djibo (3) } & \multicolumn{3}{|c|}{$P$ value $(*)$} \\
\hline & $\mathrm{N}$ & Median & Q25 & $\overline{Q 75}$ & $\mathrm{~N}$ & Median & Q25 & $\overline{Q 75}$ & $\bar{N}$ & Median & Q25 & $\overline{Q 75}$ & $1 \mathrm{vs} 3$ & $2 \mathrm{vs3}$ & 1 vs 2 \\
\hline User fees for delivery & 2 & 400 & 400 & 400 & 5 & 200 & 200 & 200 & 266 & 900 & 900 & 900 & 0.001 & 0.001 & 0.102 \\
\hline \multicolumn{16}{|l|}{ Medecine/ } \\
\hline consummable fees (to health professional) & 4 & 237.5 & 138 & 650 & 40 & 1500 & 925 & 1800 & 11 & 1000 & 600 & 2200 & 0.297 & 0.001 & 0.001 \\
\hline \multicolumn{16}{|l|}{ Medecine/ } \\
\hline consummable fees (to pharmacist) & 21 & 100 & 0 & 300 & 22 & 1000 & 800 & 1650 & 40 & 1815 & 1000 & 2250 & 0.014 & 0.419 & 0.004 \\
\hline Cleaning product fees & 205 & 200 & 200 & 200 & 240 & 196 & 150 & 300 & 240 & 150 & 100 & 300 & 0.679 & 0.016 & 0.002 \\
\hline Total medical expenses & 282 & 150 & 0 & 300 & 275 & 200 & 150 & 700 & 266 & 1075 & 1000 & 1275 & 0.001 & 0.001 & 0.002 \\
\hline
\end{tabular}

$1=$ Sebba, $2=$ Dori, $3=$ Djibo $(*)$ Differences are considered to be significant when the $\mathrm{P}$ value is $<0.05$. The median has been measured among the women that paid. 
Table 5 Prevalence of excessive spending within total and partial exemption districts

\begin{tabular}{|c|c|c|c|c|c|c|c|c|c|}
\hline \multirow[b]{2}{*}{$\mathrm{K}$ value } & \multirow{2}{*}{$\begin{array}{l}\text { Threshold } \\
\text { (Djibo) }\end{array}$} & \multicolumn{8}{|c|}{$\%$ of households with excessive spending } \\
\hline & & Sebba & Djibo & AD (\%) & RD (\%) & Dori & Djibo & $A D(\%)$ & RD (\%) \\
\hline $\mathrm{k}=0.5$ & 1413 & 1.1 & 22.5 & 20.3 & 100 & 17.5 & 22.5 & 2.8 & 13.8 \\
\hline $\mathrm{k}=1.0$ & 1550 & - & 17.5 & 18 & 100 & 14.9 & 17.5 & 3.1 & 17.2 \\
\hline \multirow[t]{2}{*}{$\mathrm{k}=1.5$} & 1688 & - & 12.0 & 17.7 & 100 & 13.1 & 12.0 & 4.6 & 26.0 \\
\hline & Threshold & \multicolumn{8}{|c|}{$\%$ of households with excessive spending } \\
\hline K value & & \multicolumn{2}{|l|}{ Sebba } & \multicolumn{2}{|l|}{ Dori } & \multicolumn{2}{|l|}{$A D(\%)$} & \multicolumn{2}{|l|}{$\mathrm{RD}(\%)$} \\
\hline$k=0.5$ & 975 & \multicolumn{2}{|l|}{1.1} & \multicolumn{2}{|l|}{17.5} & \multicolumn{2}{|l|}{21.5} & \multicolumn{2}{|l|}{95.3} \\
\hline $\mathrm{k}=1.0$ & 1250 & \multicolumn{2}{|l|}{-} & \multicolumn{2}{|l|}{14.9} & \multicolumn{2}{|l|}{17.5} & \multicolumn{2}{|l|}{-} \\
\hline$k=1.5$ & 1525 & \multicolumn{2}{|l|}{-} & \multicolumn{2}{|l|}{13.1} & \multicolumn{2}{|l|}{12.0} & \multicolumn{2}{|l|}{ - } \\
\hline
\end{tabular}

$\mathrm{AD}=$ absolute difference, $\mathrm{RD}=$ relative difference.

However, fewer studies analyse the risk of further impoverishment in cases where fees have not been totally abolished or where women have to pay other out-of pocket costs at the point of use. Our study shows that total exemption of user fees, such as in Sebba, can be beneficial in reducing excessive expenses for women using delivery care. However, when the additional subsidy was not applied correctly, such as in Dori, household expenditure for direct delivery care costs did not change significantly compared to health centres with only partial exemption. In the Sebba district, where full exemption of user fees was applied, reduction of excessive health expenses was more significant in poor quintiles. It can be argued that, in case of total exemption, the positive impact on poor households would be significant and would contribute to greater equity between the poorest and the richest.

Similar to Ghana's experience, the elimination of user fees in two of Burkina Faso's districts benefitted pregnant women regardless of their socio-economic status. Ghana has introduced a similar exemption policy directed at making delivery care free. Findings showed that

Table 6 Prevalence of excessive spending by district and quintile

\begin{tabular}{lllll}
\hline & Groups & Sebba & Dori & Djibo \\
\hline \multirow{2}{*}{$\mathrm{K}=0.5$} & Q1 (poorest) & 1.6 & 18.2 & 15.9 \\
\cline { 2 - 5 } & Q5 (least poor) & 14.5 & 18.8 & 20 \\
\cline { 2 - 5 } & Q5-Q1 & 13.0 & 0.6 & 4.1 \\
\cline { 2 - 5 } & Q5/Q1 & 9.2 & 1.0 & 1.3 \\
\hline K=1.0 & Q1 & 0.0 & 14.5 & 15.9 \\
\cline { 2 - 5 } & Q5 & 10.9 & 18.8 & 18.8 \\
\cline { 2 - 5 } & Q5-Q1 & 10.9 & 4.2 & 2.9 \\
\cline { 2 - 5 } & Q5/Q1 & & 10.9 & 13.6 \\
\hline Q1 & Q5 & 0.0 & 18.8 & 15.0 \\
\cline { 2 - 5 } & Q5-Q1 & 0 & 7.8 & 1.4 \\
\cline { 2 - 5 } & Q5/Q1 & - & 1.7 & 1.1 \\
\hline
\end{tabular}

with its universal application, the policy of abolishing user fees also benefited the poor, thereby addressing the equity issue in their health system. In fact, 18 months after user fees were abolished the greatest increase in health facility use was by the poorest segment of the population [18].

This positive impact of the abolition of user fees on the health care seeking behaviour and on the out-ofpocket expenditures observed in Ghana should encourage Burkina Faso's Government to expand the full exemption pilot project to the national level.

In a country where almost $46 \%$ of the population lives below the threshold of absolute poverty [8], it is important to implement poverty reduction strategies. Full user fee exemptions could improve access to institutional birthing facilities and reduce poverty by decreasing excessive medical expenses. In fact, we already observed that access to facility-based delivery improves dramatically with the reduction of user fees. In three years, institutional deliveries increased by 35 to 50 percentage point in Sebba and Dori and only by 14 percentage point in the control district (Djibo) (see Table 4). Scaling up the full user fee exemption to the national level would certainly broaden its impact.

\section{Implementation gap}

Results in the three districts show inadequate implementation of the user-fee exemption, especially for Dori and Djibo. In fact, respectively $21 \%$ and $19 \%$ of the women are still paying for drugs and consumables, which should be covered under both the government's and NGO's exemptions program. During the household surveys, women reported that they were still paying for items that should be free, such as gloves, syringes and drugs. In addition, in Dori, women are still facing out-of-pocket expenses whereas all the births are supposed to be "free" to the user. When these results were shared in a workshop with different stakeholders in November 2010, health professionals from the region gave some explanations for the added expenses. The main one arising from 
the discussion was the lack of understanding and confusion regarding both exemption programs [19]. In cases where the nurses and midwives were unclear about the procedures and products included in the subsidies, the patient would end up paying. A second explanation suggested by the staff for the cost of drugs and consumables charged to users was a shortage of products in the health centre pharmacy. In some remote health centres, the pharmacy management was seen as a major challenge, forcing the women to buy the required products for the non-complicated delivery from a private pharmacy. The hypothesis given by health workers about a shortage of products needs to be verified with more qualitative research. However, a similar study in another district (Ouargaye), demonstrated that supply shortages in health centre pharmacies were very rarely involved in the additional expenses incurred by the women. Occasionally, because of the absence of the community pharmacy manager, health workers send patients to a private pharmacy in the village. The study, conducted in a single district, confirmed, measured, and explained why the flat fee was not respected when the policy was implemented. Because this situation has been shown to exist in other districts of the country, it is reasonable to believe that it is a national problem.

The role of drug supply shortages was not really confirmed. However, the combination of three factors: i) products not included in the delivery kit, ii) lack of understanding of the exemption policy and iii) informal charges by health workers; explains part of the implementation gap of the policy at the local level. Nonetheless, more qualitative research is needed to understand all the plausible causes of this gap [20].

Information about the specific components of the exemption policy remains fragmented and uncertain. These problems of implementation and policy understanding are confirmed in two other studies in Burkina Faso [21]. In Nouna and Ouargaye, two regions where the national exemption policy has been evaluated recently, the level of medical expenses is very similar to those in the partial exemption district of this study, Djibo [22]. The medical expenses are usually higher than the designated user fees (900 F CFA), such as in Djibo where $50 \%$ of women (median) declared paying more than $1075 \mathrm{~F}$ CFA. The policy implementation gap appears to have more severe consequences in Dori and Djibo because the amount paid is much more than the one in Sebba. It represents at least 4 days of earnings for those who are living below the poverty line $(46 \%$ of the population). This difference between Sebba and Dori could be explained by the fact that Sebba has a Chief Medical Officer with better leadership to implement an effective monitoring and control system to more effectively implement the total exemption policy. A study in
Burkina Faso shows how the leadership of the District Chief Medical Officer (DCMO) could affect the performance of the District [23]. This seems to be the case in Dori and Sebba. For example, in 2010 the DCMO of Sebba was able to find a scholarship to obtain a master's degree and in 2012 the DCMO of Dori was transferred by the administration, reflecting that all health indicators are worse in Dori than Sebba over the last five years (see Table 4). However, further qualitative studies must be done to understand in depth this difference between the two districts. For example, it is crucial to analyse how the NGO monitoring and evaluation system responded to the different leadership in both districts. Finally, the results show that the policy instrument of the abolition of user fees is not enough; the implementation process as well as a thorough monitoring system to reduce the risk of implementation gap are essential [24, 25].

In addition, in Burkina Faso, the fixed-rate reimbursement of services represents a profound change to health administration practices, designed to reduce the work burden of health professionals. However, the administration in general in Burkina Faso is more bureaucratic and demands detailed proof for every health service delivered, even with a fixed-rate reimbursement system. This lack of alignment resulted in fixed-rate reimbursement under an actual-cost accounting system. Thus, one important weakness is that the accounting control system is not set up for fixed-rate reimbursement, and discussions are on-going to return to a system based on real expenses, as the actual costs for births are less than the fixed-rate reimbursement. Thus, the implementation gap can also be explained by this administrative conflict between practice and accountability. In fact, health professionals have a financial interest in reducing the real amount of used input to make a profit on the fixed-rate received for the service. Furthermore, despite relatively tight administrative controls, it seems that health workers have figured out how to take advantage of the system $[23,26]$. It demonstrates once again the necessity to review policy instruments to improve its effectiveness.

The process of policy development and implementation has itself an important influence on effective implementation. In fact, the potential for a "no user fee" policy to translate into reduced mortality and morbidity for mothers and babies depends fundamentally on the effectiveness of its implementation. The NGO implemented a system of monitoring and control of the exemption system in all the health centres in Dori and Sebba. They also supported health centres in running and maintaining their facilities, by building the capacity of the healthcare and administrative staff as well as community health management committees. The NGO also initiated activities to raise community awareness of maternal healthrelated issues. They use a reimbursement form based on 
lump sum per delivery that coincides with a flat rate of 900 F CFA. However, findings demonstrate that there is a need for a strong monitoring and evaluation component to address problems related to partial and full policy implementation at the local and national levels, including effective and thorough dissemination of the policies to the communities and health workers [26].

\section{Strengths and limitations}

The adequacy of the study design and the degree of control exercised in the data gathering enhanced the internal validity. The random assignment of the sample and the control of external variables within the districts ensured the analysis of the change in the dependent variable (household expenses). In addition, at any given value of $\mathrm{k}$, findings show the same type of association between the percentage of households with excessive spending and the group affiliation. This homogeneity enhances the reliability of the findings.

One limitation of this study is the potential for recall or memory bias. These measure biases can occur while collecting information about the extent and types of outof-pocket expenditures by women/households for noncomplicated institutional birthing services in the selected health centres. In order to reduce this type of systematic error regarding childbirth expenditures, researchers attempted to limit the period between interviews (May 2010) and time of birth to a maximum of 2 months. However, in cases where total number of deliveries during this period was not sufficient ( $<50$ women) the period of selection was extended up to 6 months prior to May 2010. This date extension was made only for the comparison district sample.

Another limitation is the lack of data in the districts of Dori and Sebba before the HELP intervention in 2008. In fact, we do not possess the information about the household expenses related to institutional delivery prior to the HELP pilot. Such data would have increased the internal validity of the study. Thus, in a context of natural experimentation, the case-control design is the best design to conduct such study.

The partial exemption district also had some limitation when it comes to analysing the istricts characteristics (Table 4). However, choices of districts for comparison were very limited. Therefore, there are challenges to the evaluation of public health policy interventions as natural experiments because of the lack of control over the study conditions [11]. To reduce this challenge as much as possible, Djibo, which has characteristics most like to Dori and Sebba, was chosen for the study.

\section{Conclusions}

The results of this study are particularly encouraging. They show that the abolition of payment for facility- based births is a solution that is not only equitable, but also potentially useful in reducing the proportion of women for whom excessive medical expenses represent a serious risk to their household well-being. However, the implementation gap in Dori is a lesson to keep improving the monitoring system related to medical expenses at the point of use. Furthermore, additional research is needed to understand factors associated with the "success" of total exemption intervention in Sebba. For example, the leadership of the District Medical Officer must be studied as well as positive and negative incentives that may be used to allow effective application of the exemption at health centre level.

During the study, the government's partial exemption was based on fixed-rate reimbursement (lump sum flat fee). However, for uncomplicated births, the fixed rate costs were never compared to actual costs of care delivery. The government set the cost for an uncomplicated birth at 4500 F CFA. This included the cost of the delivery kit (drugs and consumables). Women thus have to pay 900 F CFA for uncomplicated births (20\%). These expenses were supposed to be included in the national budget for the period 2006-2015, evidence of a real political commitment to reducing maternal mortality and morbidity. However, many studies demonstrated that the fixed rate fee structure is higher than the real cost of uncomplicated births (gap of -17 to -27 between 2006 and 2008). Consequently, abolishing the 900 FCFA payment as promised by the Head of State in February 2010 appears feasible, as long as mechanisms are in place to eliminate informal charges. Indeed, the district of Kaya abolished the 900 FCFA payment without any NGO assistance by using its decentralized credits mechanisms. Furthermore, since 2011 in Djibo and 2012 in GorumGorum the local municipalities have paid the 900 F CFA user fees, showing that political will At local level can reduce financial barriers. Full exemption for all from point-of-service user fees should be considered in order to move toward universal coverage [27, 28]. The President of Burkina Faso is therefore accurate when he stated in 2010 that he would embark on completely removing the direct payment for facility-based births. This decision has yet to be implemented, while this study shows how it would be beneficial to women. Therefore, it is now urgent to abolish user fees for births because the State has the financial means to do so. Furthermore, international donors should also reorient their interest on achieving universal health coverage by supporting government implementing total abolition of user fees as an effective strategy toward equity and poverty reduction in developing countries. At the same time, the State must find ways to ensure effective implementation of its policies by making sure that they are clearly understood and by establishing accountability mechanisms. In 
fact, this study demonstrates clearly that the policy instrument of the abolition of user fees is not enough; the implementation process is essential and needs a thorough monitoring system to reduce the risk of implementation gaps [11].

\section{Competing interests}

The authors declare that they have no competing interests.

\section{Authors' contributions}

VR and $L Q$ were in charge of the original study design. VR, $A B$ and $A B A$ designed the data collection tools. AB, ABA and $L Q$ were responsible for data collection. $A B, A B A, M G I$ and $V R$ conducted the data analysis. All authors contributed to the interpretation of the results. $A B A, M G I$ and VR wrote the manuscript with contributions from all authors. All authors had full access to all of the data (including statistical reports and tables) in the study and can take responsibility for the integrity of the data and the accuracy of the data analysis. All authors read and approved the final manuscript.

\section{Acknowledgements}

The authors extend sincere thanks to all the local actors involved in the study, especially to the communities in the Sahel region. The authors thank the data collectors and supervisors for their diligent work. Finally, the authors thank Kevin Conway (IDRC) and Annette Hollman (CHUM) for their help in in editing the manuscript. This study was made possible by " Service d'aide humanitaire de la Commission européenne (ECHO)" and "Fonds pour la Recherche en Santé du Québec (FRSQ)". Amal had a research grant from the International Development Research Center (IDRC). Valéry Ridde is the recipient of a salary grant from the Canadian Institutes of Health Research (CIHR).

\section{Author details}

IInternational Development Research Centre (IDRC, Ottawa, Canada. ${ }^{2}$ Centre de recherche du Centre Hospitalier de I'Université de Montréal, Montréal, Québec (CRCHUM), Canada. ${ }^{3}$ Department of Social and Preventive Medicine, Université de Montréal, Montréal, Québec, Canada. ${ }^{4}$ Institut de Recherche en Sciences de la Santé (IRSS, Ouagadougou, Burkina Faso.

Received: 4 November 2011 Accepted: 26 October 2012

Published: 21 November 2012

\section{References}

1. Richard F, Witter S, de Brouwere V: Innovative Approaches to Reducing Financial Barriers to Obstetric Care in Low-Income Countries. Am J Public Health 2010, 100:1845-1852.

2. Nanda P: Gender dimensions of user fees: implications for women's utilization of health care. Reprod Health Matters 2002, 10(20):127-134.

3. Mclntyre D, Thiede M, Dahlgren G, Whitehead M: What are the economic consequences for households of illness and of paying for health care in low- and middle-income country contexts? Soc Sci Med 2006, 62:858-865.

4. African Union: Fifteenth Ordinary Session 25-27 July 2010, Assembly of the African Union. Report on actions on maternal, newborn and child health and development in Africa by 2015. Kampala, Uganda: 2010. http://www.unfpa. org/webdav/site/global/shared/documents/news/2010/ kampala_au_assembly_dec.pdf.

5. Meessen B, Hercot D, Noirhomme M, Ridde V, Tibouti A, Tashobya CK, Gilson L: Removing user fees in the health sector: a review of policy processes in six sub-Saharan African countries. Health Pol Plann 2011, 26 (Suppl 2):ii16-ii29.

6. Sambo L, Kirigia J, Ki-Zerbo G: Perceptions and viewpoints on proceedings of the Fifteenth Assembly of Heads of State and Government of the African Union Debate on Maternal, Newborn and Child Health and Development. BMC Proc 2011, 5(Suppl 5):S1.

7. WHO, UNICEF, UNFPA: The World: Trends in Maternal Mortality: 1990 to 2008. Global Health Observatory (GHO).

8. Bilan Commun de Pays (CCA) et Plan Cadre des Nations Unies pour l'Aide au Développement (UNDAF), Programme des Nations Unies pour le développement (PNUD), 20044. site web: http://www.pnud.bf/fr/cca_undaff. $\mathrm{htm}$.

9. Amnesty International: Giving life, risking death-maternal mortality in Burkina Faso. 2009.
10. WHO: The world health report: health systems financing: the path to universal coverage. 2010:p.106.

11. Petticrew M, Cummins S, Ferrell C, Findlay A, Higgins C, Hoy C, et al: Natural experiments: an underused tool for public health? Public Health 2005, 1199:751-7

12. Queuille L, Ridde V, Diallo I: Étude des processus d'exemption du paiement des soins dans deux districts de la région du sahel- Burkina Faso. 2010.

13. Queuille L, Ridde V, Seguin J: Etude d'une série de cas à propos des délais de remboursement du projet d'exemption du paiement des soins de l'ONG HELPBurkina Faso. 2010.

14. Ridde V, Kouanda S, Bado A, Bado N, Haddad S: Reducing the Medical Cost of Deliveries in Burkina Faso Is Good for Everyone, Including the Poor. PLOS ONE. 2012, 73:e33082. doi:10.1371/journal.pone.0033082.

15. Lindelow M: Sometimes more equal than others: how health inequalities depend on the choice of welfare indicator. Heal Econ 2006, 15:263-79.

16. Filmer D, Pritchett LH: Estimating wealth effects without expenditure data-or tears: an application to educational enrollments in states of India. Demography 2001, 38:115-132.

17. Mukherje S, Haddad S, Narayana D: Social class related inequalities in household health expenditure and economic burden: evidence from Kerala, south India. International Journal of Equity Health 2011, 10:1.

18. Witter S, Adjei S, Armar-Klemesu M, Graham W: Providing free maternal health care: ten lessons from an evaluation of the national delivery exemption policy in Ghana. Global Health Action 2009.

19. Sombié I, Yaogo M, Ouédraogo M, Konaté B, Belemsaga D, Ouédraogo T: Evaluation de la mise en place de la subvention des accouchements et des soins obstétricaux et néonataux d'urgence au Burkina, Rapport préliminaire, Ministère de la Santé, Groupe de Recherche, d'Expertise et de Formation en Santé pour le Développement, (GREFSAD). Ouagadougou: 2007.

20. Ridde V, Kouanda S, Yameogo M, Kadio K, Bado A: Why do women pay more than they should? A mixed methods study of the implementation gap in a policy to subsidize the costs of deliveries in Burkina Faso. Eval Program Plann. http://dx.doi.org/10.1016/j.evalprogplan.2012.09.005.

21. Ridde V, Richard F, Bicaba A, Queuille L, Conombo G: The national subsidy for deliveries and emergency obstetric care in Burkina Faso. Health Policy Plan 2011, 26(suppl2):ii30-ii40. doi:10.1093/heapol/czr060.

22. De Allegri M, Ridde V, Sarker M, Müller O, Jahn A, Louis VMY, Tiéndrebeogo $\mathrm{J}$ : The impact of targeted subsidies for facility-based delivery on access to care and equity - Evidence from a population-based study in rural Burkina Faso. J Public Health Policy 2012 Nov;33(4):439-53. doi:10.1057/ jphp.2012.27.

23. Germain B: NAMA Enquêtes parlementaires: Comment les subventions publiques à la santé sont détournées? 2012. http://www.lefaso.net/spip.php? article48798.

24. Haddad S, Bicaba A, Feletto M, Fournier P, Zunzunegui MV: Heterogeneity in the validity of administrative-based estimates of immunization coverage across health districts in Burkina Faso: implications for measurement, monitoring and planning. Health Policy Plan 2010, 25 (5):393-405. Epub 2010 Feb 25.

25. Gilson L, Mclntyre D: Removing user fees for primary care in Africa: the need for careful action. Br Med J 2005, 331:762-5.

26. Ridde $\mathrm{V}$ : The problem of the worst-off is dealt with after all other issues: the equity and health policy implementation gap in Burkina Faso. Soc Sci Med 2008, 66(6):1368-1378.

27. Ridde V, Richard F, Bicaba A, Queuille L, Conombo G: The national subsidy for deliveries and emergency obstetric care in Burkina Faso. Health Policy Plan 2011, Supplement 2(26):ii30-ii40.

28. Ridde V, Robert $E$, Meessen B: A literature review of the disruptive effects of user fee exemption policies on health systems. BMC Publ Health 2012, 12:289.

doi:10.1186/1472-6963-12-412

Cite this article as: Ameur et al.: User fee exemptions and excessive household spending for normal delivery in Burkina Faso: the need for careful implementation. BMC Health Services Research 2012 12:412. 